\title{
The effect of forward and backward implicit verbal chaining on paired-associate learning
}

RICHARD L. TAYLOR

UNIVERSITY OF OREGON

\begin{abstract}
The relative effect of $\mathrm{A}-\mathrm{B}-\mathrm{C}$ forward and backward associative chains, where $B$ was an implicit term not appearing in the experiment, was investigated in a two-stage (X-A, X-C or X-C, X-A) paired-associate task. The results indicated significant stage 2 facilitation for forward but not for backward associative chains. Problem
\end{abstract}

A number of investigators have obtained facilitation due to implicit mediating verbal associations (Cofer \& Yarczower, 1957; McGehee \& Schulz, 1961; Russell \& Storms, 1955)。Typically in these studies Ss learn paired associates $\mathrm{X}-\mathrm{A}$ to criterion, and then are tested for acquisition of $\mathrm{X}-\mathrm{C}$ in a second stage. Since word association norms indicated strong $\mathrm{A} \rightarrow \mathrm{B}$ and $\mathrm{B} \rightarrow \mathrm{C}$ linkages in the absence of $\mathrm{A} \rightarrow \mathrm{C}$ associations, the implicit role of $\mathrm{B}$ as a mediator and of an $\mathrm{A} \rightarrow(\mathrm{B}) \rightarrow \mathrm{C}$ chain has been presumed to be critical in facilitating learning. It is not clear from these studies, however, to what degree backward, or R-S associations may have contributed to the results. Since no data was available on $\mathrm{C} \longrightarrow \mathrm{B}, \mathrm{B} \rightarrow \mathrm{A}$, or $\mathrm{C} \longrightarrow \mathrm{A}$ associations, it may have been, for example, that the test trials were facilitated by a normally explicit $\mathrm{C} \rightarrow \mathrm{A}$, or $\mathrm{R}-\mathrm{S}$ associative linkage rather than by an S-R implicit associative chain.

The purpose of this study was to compare the effects of forward and backward implicit verbal association chains when possibilities for both forward and backward "short-circuiting"' were controlled, and where the relative strengths for all key linkages were known. Method

Using a sample base of 120 students at Occidental College, Los Angeles, a series of word association norms were drawn until $8 \mathrm{~A} \rightarrow \mathrm{B} \rightarrow \mathrm{C}$ word chains and 8 control words were obtained with the following restrictions: (a) no control word appeared as an associative response or as a stimulus for any other word used in the experiment, (b) no word in any chain appeared as a response to any word used in any other chain, and (c) the frequency of reverse associations for words used in each $\mathrm{A} \rightarrow \mathrm{B} \rightarrow \mathrm{C}$ chain precluded the possibility of their serving also in a $\mathrm{C} \rightarrow \mathrm{B} \rightarrow \mathrm{A}$ chain. Eight nonsense syllables (X) used previously by Russell \& Storms (1955) were included to make up a two-stage task involving $\mathrm{X}-\mathrm{A}$ and $\mathrm{X}-\mathrm{C}$ paired associates (forward implicit chaining) as well as $\mathrm{X}-\mathrm{A}, \mathrm{X}-\mathrm{Z}$ (control words) in List 1 , and $\mathrm{X}-\mathrm{C}, \mathrm{X}-\mathrm{A}$ (reverse implicit chaining) with $\mathrm{X}-\mathrm{C}, \mathrm{X}-\mathrm{Z}$ in List 2. Five presentation orders of each stage were developed to minimize serial learning, with each order serving equally often as the starting order.

The Ss were 48 Occidental College students, none of whom had participated in establishing the original word norms. They were assigned at random to either forward or reverse chaining conditions, with each $\mathrm{S}$ serving as his own control for test trial facilitation effects. All Ss learned stage 1 (either X-A or X-C) to a criterion of 3 perfect trials. Following a 2 min. rest interval, all Ss then responded to stage 2 paired associates for 15 trials, or up to one perfect recitation. All learning was at a $3.5: 1-\mathrm{sec}$. rate of presentation with a 5.5-sec. intertrial interval on a specially adapted Kodak Carousel slide projector. The words were typed on slide mounts and projected a distance of $6 \mathrm{ft}$ onto a standard fold-up movie screen. Ss responded orally in anticipating the paired associates.

\section{Results and Discussion}

The mean number of trials to a criterion of 3 perfect recitations during stage 1 was 9.88 and 9.50 for the forward and reverse groups, respectively. The difference between these means was not significant, $t<1.0$, indicating that the groups were comparable in terms of learning ability. No intra-S comparisons of mean number of trials to criterion between stage 1 items serving as control or experimental paired associates in stage 2 were significant $(p<.10)$, indicating that the A and $\mathrm{C}$ portions of the word chains used did not differ in difficulty.

Because the distribution of correct responses to criterion in stage 2 was highly skewed, Wilcoxon Tests were used to evaluate the effects of implicit verbal mediators on performance. The mean number of correct anticipations for the Ss on forward chains and their control pairs were 14.68 and 10.32 , respectively. Using a normal approximation of $t$, this difference was significant $(z=3.26, p<.001)$, indicating that the forward implicit verbal mediation chains facilitated learning. The differences between backward associative chains and their controls, however, proved not to be significant $(z=.79, p>.05)$. Differences between mean number of correct anticipations for the two control groups also were not significant $(t<1.00)$, indicating that the forward and reverse chaining effects were not evaluated according to different baselines.

This data is consistent with other findings noted in the literature which indicates facilitation of criterion learning due to the presence of implicit verbal mediators associatively linked in a forward direction to words 
used experimentally. There is no evidence that this effect functions in a backward direction across an implicit mediator.

\section{References}

Cofer, C. N., \& Yarczower, M. Further study of implicit verbal chaining in paired-associate learning. Psychol. Rep., 1957, 3, 453-456.

McGehee, N., \& Schulz, R. Mediation in paired-associate learning. J. exp. Psychol., 1961, 52, 565-570.
Russell, W. A., \& Storms, L. H. Implicit verbal chaining in pairedassociate learning. J. exp. Psychol., 1955, 49, 287-29

\section{Note}

1. This article is based upon a thesis submitted to the Department of Psychology, Occidental College, in partial fulfillment of the requirements for the M.A. degree. The author is grateful to D. Cole and L. Jennings for their suggestions and criticisms.

\section{Erratum}

Bogartz, W., \& Headrick, A. The length-difficulty law of serial learning: An empirical function and a theoretical derivation. Psychon. Sci., 1965, 3, 357-358. On page 358 , equation (1) should read

$$
e_{n+1}=(1-\theta) e_{n}
$$

and equation (5) should read

(5)

$$
E=\left(r-e_{t+1}\right) / \theta
$$

